\title{
Clinical features of vernal keratoconjunctivitis: A population study of primary school children in Nigeria
}

\author{
Roseline E. Duke*1, Eni Egbula ${ }^{1}$, Stefan De Smedt ${ }^{2}$ \\ ${ }^{1}$ Department of Ophthalmology, Calabar Children's Eye Center, University of Calabar Teaching Hospital, Calabar, Cross River \\ State, Nigeria \\ ${ }^{2}$ Department of Ophthalmology, AZ St Maarten Hospital, Mechelen, Belgium
}

Received: December 4, 2016

Accepted: June 20, 2017

Online Published: July 27, 2017

DOI: $10.5430 /$ jer.v3n2p44

URL: https://doi.org/10.5430/jer.v3n2p44

\begin{abstract}
Objective: The objective of the study is to describe pertinent clinical features of vernal keratoconjunctivitis (VKC) seen in public primary school children in Nigeria, Africa.

Methods: A cross sectional survey of children with VKC was conducted in a population of school children using a multistage sampling method. Comprehensive eye examinations were conducted including visual acuity, refraction, anterior and posterior segment examinations, ocular adnexal examinations and symptomatic break up time (SBUT) for tear assessment.

Results: Out of 1,226 primary school children examined, 223 children had VKC. The most common complaints were itching $150(67.3 \%)$, brownish discoloration of the eyes $132(59.2 \%)$ and stringy mucoid discharge $109(48.9 \%)$. The total prevalence of atopy in this population was $30 \%$. Normal vision was seen in $223(100 \%)$ children, while $5(0.9 \%)$ children presented with monocular moderate visual impairment. Ptosis from VKC was seen as a significant $(p<.0001)$ finding in the tarsal clinical type $55(24.7 \%)$ and 60 (26.9\%) right and left eyes respectively. Left eye lid chalazion was also significantly associated with tarsal type of VKC $(p<.0001)$. Common corneal complications noted were sub epithelial scarring $22(9.9 \%)$ and pseudogerontoxon 7 $(3.1 \%)$. Symptomatic tear film break-up time of $<5$ seconds was seen more frequently among children 156 (70\%) with VKC even though this was not statistically significant $(p=.737)$.

Conclusion: The clinical features of VKC is similar to most population studies, including corneal complications. Eye lid pathologies including chalazion, external hordealon and ptosis were common features seen in this population. Better primary eye care for the management of VKC in children may prevent corneal complication.
\end{abstract}

Key Words: Vernal keratoconjunctivitis, Clinical features, Nigeria, Primary eye care

\section{INTRODUCTION}

Vernal keratoconjunctivitis (VKC) is included in the newest classification of ocular surface hypersensitivity disorders as both an IgE- and non-IgE mediated ocular allergic disease. ${ }^{[1]}$ The ocular surface is directly exposed to the external environment, and is therefore endangered by both antigens and pathogenic microorganisms. The ocular surface can be described as a group of tissues which include the cornea and its major support tissue, the conjunctiva. It also includes the ocular mucosal adnexa, the lacrimal gland and the lacrimal drainage system. ${ }^{[2]}$ An important function of the ocular surface is to protect the eye from injury, infection, and desiccation. ${ }^{[3]}$

Recent clinical observations show that the conjunctiva is not

\footnotetext{
*Correspondence: Roseline E. Duke; Email: dr.roselineduke@gmail.com; Address: Department of Ophthalmology, Calabar Children’s Eye Center, University of Calabar Teaching Hospital, Calabar, Cross River State, Nigeria.
} 
the only tissue affected in ocular allergic conditions. Other tissues of the eye are also involved in the ocular allergic reaction, like the eye lids, with their high content of mast cells, the tear film, with its immunoglobulins, and the cornea, which is vital for visual function. ${ }^{[3-5]}$

New investigations regarding the pathogenesis of ocular allergies indicate that the participation of the entire ocular surface in allergic diseases is not only the consequence of tissue contiguity but derives from a complex exchange of information between these tissues through cell-to-cell communications, chemical mediators, cytokines, and adhesion molecules. ${ }^{[1]}$ The results of these complex interactions in vernal keratoconjunctivitis presents a clinical picture which has characteristic features and public health implications.

This study describes the clinical features of VKC, in public primary school children in Nigeria, and explores the health seeking behavior of affected children.

\section{Method}

\subsection{Study setting}

The study was conducted in Calabar South Local Government Area (LGA) of Cross River State, Nigeria, from September to December 2014 in the early dry season. The Calabar South Local Government Area covers an area of $264 \mathrm{~km}^{2}$ with a density of 725.4 inhabitants $/ \mathrm{km}$ and a population of 191,630. Calabar South also records an average annual rainfall amount of $3000 \mathrm{~mm}$ with relative humidity of above $85 \%$. The area is characterized by double maximum rainfall that climaxes in the months of July and September. ${ }^{[6]}$

In Calabar South Local Government Area there are 11 primary health centres, 6 health posts, 1 general eye clinic and a tertiary child eye care facility. The Cross River State Eye Care program provides community pediatric eye care services.

\subsection{Study population}

The study population comprises of public primary school pupils in Calabar South Local Government Area of Cross River State. The inclusion criteria were: children aged 4 years to 15 years in public primary schools including children who were absent from school on the day of examination. Exclusion criteria included other causes of allergic conjunctivitis. The study design was a cross sectional study.

\subsection{Sample size calculation}

The sample size calculation for a single proportion where the population is $>10,000$, gave a total sample for the cross sectional study as 1,500 children in five schools. This was calculated thus:

Published by Sciedu Press
The standard normal deviate of 1.96 was used, with a prevalence of outcome of interest (VKC) as $3 \%{ }^{[7]}$ and a level of precision of $5 \%$. The non-response rate was set at $10 \%$. These resulted in a sample size calculation of 50 children per class. Public schools have six class sets, therefore a total of 300 children were examined per school. The sampling frame was composed of a list of all public primary schools in the Calabar South Local Government Area as well as a list of the children registered in the primary school classes. Some of the children that did not attend school on the day of the visit were traced and interviewed. Parents were invited for an interview on the school visit day. Informed consent was obtained from parents/guardians.

\subsection{Sampling method}

Multistage sampling method was used to recruit participants. There are 21 primary schools in Calabar South Local Government. In the first stage, five public primary schools were randomly selected by balloting from the list of 21 schools. In the second stage, simple random sampling method (through balloting) was used to select the classes in the chosen schools. With the use of an existing register from the selected schools, class sets were used from primary one (1) through primary six (6) to select the 6 classes to be used for the study. For recruitment of children into the study, systematic random sampling was used to select 50 children per class if the number of children was more than 50, leading to the recruitment of 300 students for per school. The identity of each child was cross checked against the class register which was in the custody of the class teacher. Cases of VKC were sought and identified within the target population of 1,500 children. Selected children who were not in school on the day of the examination and whose homes were accessible were traced and examined. Children whose homes could not be accessed and whose parents were not available to give a history and consent were not included in the study. Therefore, only 1,226 children were examined. ${ }^{[8]}$

\subsection{Interview and examination}

Data collection entailed interview on socio-demography and ocular history from parents. Systemic and eye examinations were conducted on every child by a team of an ophthalmic nurse, optometrist, pediatrician and ophthalmologist.

\subsection{Operational definition}

Atopy refers to a family history of allergic diseases such as allergic rhinitis, asthma and atopic dermatitis (eczema). ${ }^{[9]}$

Rhinitis was defined as a history of recurrent inflammation of the mucous membrane of the nose, presenting by nasal congestion. ${ }^{[10]}$ Asthma was diagnosed on the basis of history and wheezing on auscultation after exercise challenge. ${ }^{[11]}$ 
Eczema was defined using the criteria of Hanifin and Rajka World Health Organization categories. ${ }^{[12]}$ The WHO grade of visual acuity (VA) and impairment was used which included normal: $6 / 5->6 / 12$; mild $<6 / 12$ to $\geq 6 / 18$; moderate $<6 / 18$ to $\geq 6 / 60$; severe $<6 / 60$ to $\geq 3 / 60$; blind $<3 / 60$. $^{[13]}$ Significant refractive errors were defined as hyperopia $\geq$ $3.00 \mathrm{D}$, myopia $\geq 1.00 \mathrm{D}$ or astigmatism $\geq 1.50 \mathrm{D}$ in either eye, or anisometropia $\geq 2.00 \mathrm{D}$ and were based on the service provision criteria for free spectacles provision used by the Cross River State Eye Care programme. Ptosis was defined in terms of the mid-pupil to upper lid distance. ${ }^{[14]}$ Physical measurements included detailed ocular adnexal examinations, anterior and posterior segment examinations using a portable slit lamp (Reichert 15090 - PSL Portable Slit Lamp 2014) and a Keller direct ophthalmoscope. Visual acuity assessments using the Snellen chart and refraction with a Zeiss autorefractor model 2006 were performed. The symptomatic break up time (SBUT) test is defined as the time (in seconds) that transpires between the last complete blink and the moment the children experience ocular discomfort. This SBUT test was conducted as follows after explaining to the child:

(1) A stop watch or clock was used on the iPad Air.

(2) The child was asked to blink two times and then asked to stare straight ahead.

(3) The child was instructed to avoid blinking for as long as possible and to indicate when ocular discomfort began. This was defined as itchiness, foreign body sensation, too much air entering the eyes and pain. The timer was started at the moment of last blink.

(4) The timer was stopped at the moment of ocular awareness which was represented by a blink.

(5) The length of time (in seconds) that transpired between the last complete blink and the moment ocular discomfort was experienced was recorded as the SBUT. ${ }^{[15,16]}$

\subsection{Data management or analysis}

Data was entered into a Microsoft Excel sheet and analyzed using statistical package for social sciences (SPSS) for Windows (version 20, SPSS Inc., Chicago, IL, USA). The confidence level of $95 \%$, the level of significance was set at $p<$ .05 .

\subsection{Ethical approval}

Ethical approval was obtained from the Cross River State Ministry of Health Ethical Review Board and the study was in accordance with the Declaration of Helsinki. The ethical clearance did not permit conducting a cycloplegic refraction during the school visit or transporting patients for further examination to the Calabar Children's Eye Centre by the research team. However, parents were invited to visit the facility on their own volition.

\section{RESULTS}

Out of 1,226 public primary school children, cases of vernal keratoconjunctivitis in different stages of the disease was seen in $223(18.1 \%)$ children. ${ }^{[8]}$ The description of the sociodemographic characteristics, atopy and clinical types of VKC are reported in Tables 1 and 2. Males were more likely to develop any type of VKC than females, but these differences were not statistically significant $(p=.166)$. All the three clinical types of VKC were significantly more among the 6-10 age group $(p=.028)$.

Children with VKC that did not seek or receive any form of treatment for the condition were $(n=174 / 223,78.0 \%)$, this was statistically significant $(p=.051)$. Children treated at home were $(n=2,0.9 \%)$ and they all had mixed type of VKC. Unknown medications were administered over the counter by patent medicine vendors (PMV) to $(n=13,5.8 \%)$ children. Among those treated by the PMV, 1 child had limbal, 5 had tarsal and 7 children had mixed VKC. There was no report that any child had been taken to a traditional healer, medical doctor, general or eye clinic. However, $(n=33,14.8 \%)$ parents/care givers did not respond to the question.

Figure 1 shows the common presenting complaints. Itching, brownish discoloration of the eye and stringy mucoid discharge were the most frequent. Droopy lids $(p<.026)$ and stringy mucus discharge $(p<.014)$ were significantly associated with the tarsal clinical type.

The total prevalence of atopy in this population was $n=67$, $30 \%$. History of drug allergies $(n=1,0.4 \%)$, skin allergies ( $n$ $=4,1.8 \%)$, and rhinitis $(\mathrm{n}=18,8.1 \%)$ were reported. VKC was significantly associated with skin allergies $(p<.032)$ and rhinitis $(p<.041)$. Clinically, atopy was seen in $(\mathrm{n}=35$, $15.7 \%)$ children with eczema and $(n=9,4.0 \%)$ with asthma. There was no statistically significant relationship between eczema $(p=.074)$, asthma $(p=.649)$ and VKC.

All the children examined had normal grade of visual acuity. However, monocular moderate visual impairment was seen in the right eye with visual acuity $<6 / 18-\geq 6 / 60$ in $(n=5$, $2.2 \%$ ) children.

Refractive errors were seen in 17 children (7.6\%). These refractive errors were not significant based on the research definition.

Eye lid excoriation was seen in 11 right eyes (Re) $(4.9 \%)$ and 12 left eyes (Le) (5.3\%). Eye lid excoriation was not significantly related to any clinical type of VKC in this study.

ISSN 2377-9306 E-ISSN 2377-9330 
Hyperpigmentation was seen in $136 \mathrm{Re}(61 \%)$ and $125 \mathrm{Le}$ $(53.6 \%)$, and this significantly occurred more frequently among the 1-5 years age group $(p=.005)$.

Ptosis was significantly more seen $(p<.001)$ in children with the tarsal clinical type of VKC (Re: $n=60,26.9 \%)$, (Le: $n=$ $55,24.7 \%)$.

External hordeolum was significantly more present in the left eyelid $(\mathrm{n}=9,4.0 \%, p<.037)$.

Chalazia were reported in 12 right (5.3\%) and 9 left eyes
$(4.0 \%)$. Left eye lid chalazion was also significantly associated with the tarsal type of $\operatorname{VKC}(p<.0001)$.

Only eighteen children $(8.1 \%)$ presented with upper tarsal conjunctiva giant papillae.

Most commeon corneal characteristics of VKC seen among the school children were, limbal papillae $(\operatorname{Re}=79,35.4 \%)$ and $(\mathrm{Le}=78,35 \%)$. This was more than $180^{\circ}$ in distribution in the 40 right eyes (17.9\%) and 38 left eyes (17.0\%). Trantas dots were seen in 39 right (17.4\%) and 40 left eyes (17.9\%).

Table 1. Demographic characteristics of VKC

\begin{tabular}{|c|c|c|c|c|c|}
\hline \multirow{2}{*}{ Clinical type of VKC } & \multicolumn{2}{|c|}{ Gender n (\%) } & \multicolumn{3}{|c|}{ Age group in years $n(\%)$} \\
\hline & Male & Female & $1-5$ & 6-10 & 11-15 \\
\hline Limbal & $40(59.7)$ & $27(40.3)$ & $1(1.5)$ & $49(73.1)$ & $17(25.4)$ \\
\hline Tarsal & $75(71.4)$ & $30(28.6)$ & $6(5.7)$ & $77(73.3)$ & $22(21.0)$ \\
\hline Mixed & $30(58.8)$ & $21(41.2)$ & $0(0.0)$ & $30(58.8)$ & $21(41.2)$ \\
\hline Total & $145(65.0)$ & $78(35.0)$ & $7(3.1)$ & $156(70.0)$ & $60(26.9)$ \\
\hline$\chi^{2}$ & 3.590 & & 11.8 & & \\
\hline$p$-value & .166 & & .028 & & \\
\hline
\end{tabular}

Table 2. Clinical characteristics of VKC

\begin{tabular}{|c|c|c|c|c|c|c|c|c|}
\hline \multirow{2}{*}{$\begin{array}{l}\text { Clinical type of } \\
\text { VKC }\end{array}$} & \multicolumn{2}{|l|}{ Eczema } & \multicolumn{2}{|c|}{ Asthma } & \multicolumn{2}{|l|}{ Rhinitis } & \multicolumn{2}{|c|}{ Other skin conditions } \\
\hline & Yes & No & Yes & No & Yes & No & Yes & No \\
\hline Limbal & $5(7.5)$ & $62(92.5)$ & $3(4.5)$ & 64 (95.5) & $6(9.0)$ & $61(91.0)$ & $1(1.5)$ & 66 (98.5) \\
\hline Tarsal & $19(18.1)$ & $86(81.9)$ & $5(4.8)$ & $100(95.2)$ & $4(3.8)$ & $101(96.2)$ & $0(0.0)$ & $105(100.0)$ \\
\hline Mixed & 11 (21.6) & $40(78.4)$ & $1(2.0)$ & $50(98.0)$ & $8(15.7)$ & $43(84.3)$ & $3(5.9)$ & $48(94.1)$ \\
\hline Total & $35(15.7)$ & $188(84.3)$ & $9(4.0)$ & $214(96.0)$ & $18(8.1)$ & 205 (91.9) & $4(1.8)$ & $219(98.2)$ \\
\hline$\chi^{2}$ & 5.22 & & 0.86 & & 6.411 & & 6.881 & \\
\hline$p$-value & .074 & & .649 & & .041 & & .032 & \\
\hline
\end{tabular}

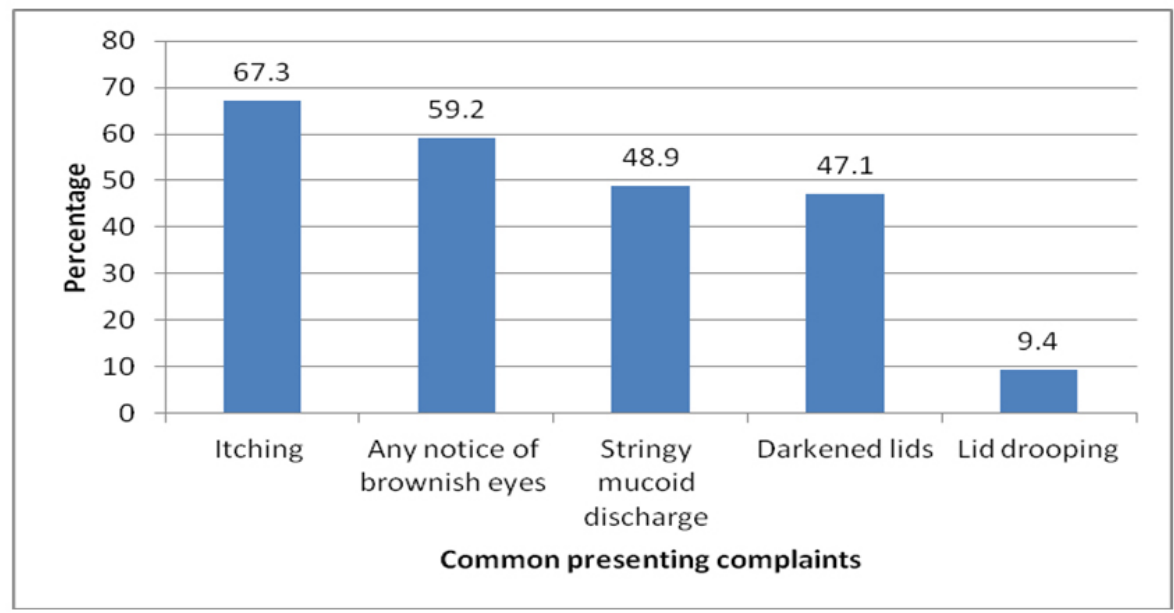

Figure 1. Common presenting complaints among patients with vernal keratoconjuctivitis 
Punctate epitheliopathy were present bilaterally in 2 children $(0.9 \%)$. There was a significant relationship between right VKC and limbal papillae $(p<.001)$ and right subepitheliopathy $(p<.001)$ but no significant relationship between VKC and right or left trantas dots $(p=.903)$ and $(p=.904)$ respectively. Sub epithelial scarring in both eyes were noted in (n $=22,9.9 \%$ ). Pseudogerontoxon was seen in 7 eyes (3.1\%).

Macroerosions, corneal ulcers, superior pannus and plaques were not reported. Subepithelial scarring was responsible for moderate visual acuity in 5 eyes $(2.2 \%)$ and this was significant $(p<.001)$.

Table 3 represents the relationship between symptomatic tear breakup and the clinical type of VKC. Symptomatic Tear film Break-up Time of $<5$ seconds was more frequently seen among children with VKC $(\mathrm{n}=156,70 \%)$ compared with a longer breakup time ( $>5$ seconds), but this difference was not statistically significant $(p=.737)$.

Table 3. Relationship between SBUT and clinical type of VKC

\begin{tabular}{|c|c|c|c|c|c|c|}
\hline \multicolumn{7}{|c|}{ Clinical type of VKC } \\
\hline SBUT & Limbal & Tarsal & Mixed & Total & $\chi^{2}$ & $p$-value \\
\hline & $67(30 \%)$ & $105(47.1 \%)$ & $51(22.9 \%)$ & $223(100.0 \%)$ & & \\
\hline \multicolumn{7}{|c|}{ Mean SBUT/sec } \\
\hline$\leq 5$ & $46(68.7 \%)$ & $76(72.4 \%)$ & $34(66.7 \%)$ & $156(70.0 \%)$ & 0.610 & .737 \\
\hline$>5$ & $21(31.3 \%)$ & $29(27.6 \%)$ & $17(33.3 \%)$ & & & \\
\hline
\end{tabular}

\section{Discussion AND CONCLUSION}

Vernal keratoconjunctivitis can jeopardize the quality of life, and school performance of affected children and hence their future potential. ${ }^{[17,18]}$ Not only can the symptoms and signs of VKC be debilitating but also the complications from its treatment.

Besides the commonly reported symptoms in VKC of stringy mucoid discharge and itching, brownish discoloration of the eye balls (59.2\%), and darkened eyelids (47.1\%) were mentioned by care givers as an important presenting complaint in our study (see Figure 1). The brownish discoloration of the bulbar conjunctiva is a result of the brown melanin pigment that has been shed into the subepithelial substantia propria which is present in macrophages (melanophages). ${ }^{[19]}$ In dark skinned people, the limbus is richer in these mast cells and melanocytes. ${ }^{[20]}$ This sign is considered to be more common in young children with VKC and not necessarily related to patient symptoms or signs of limbal disease which was seen in this study. ${ }^{[21]}$ Further, bulbar pigmentation is a specific entity in VKC, and is present in eyes with inactive disease. It is a useful clinical sign that aids diagnosis in patients with mild or quiescent disease which was predominantly seen in our study population. Periocular hyper-pigmentation which presents as darkening of the eyelid skin may result from chronic itching and rubbing on the eyelids.

Atopic conditions associated with VKC have been reported in up to $41.5 \%$ in an Italian hospital based study, with asthma more commonly reported than allergic rhinitis in VKC. ${ }^{[4]}$ Similarly, a hospital based study from Nigeria reported more asthma (6\%), than allergic rhinitis (5\%) and eczema (4.3\%) among children with VKC. ${ }^{[22]}$ Our population based study on the contrary, found the opposite: patients with VKC were significantly more associated with eczema and allergic rhinitis than asthma. Selection bias between hospital attending patients and a community sample is a possible explanation for this discrepancy. In addition, acute asthma is more likely to bring patients to the hospital rather than eczema which may go unnoticed.

Most children with VKC may have normal vision, irrespective of severity of symptoms or signs. Monocular visual impairments in our study was $9.9 \%$ and was caused by corneal complications of VKC. VKC is a cause of unilateral visual impairment in children. In a population based study in Nigeria, corneal blindness was the leading cause of monocular blindness. ${ }^{[23]}$

Acquired ptosis has generally been considered as unilateral and is not uncommonly observed in VKC. ${ }^{[17,24]}$ In contrast, our study found bilateral ptosis significantly associated with the tarsal type of VKC. This could be due to the heavy giant papillae, chronic eye rubbing, or an inflammatory insult to the levator palpebrae superioris muscle and its subsequent dis-insertion. Excoriation, chalazia and external hordeolum were significantly reported. A report by Bonini et al, observed the occurrence of blepharitis and frequent maceration. ${ }^{[17]}$ A second or co existent disease may aggravate the expression of ocular allergy. Chalazia are considered as part of the wider group of meibomian gland dysfuction (MGD) which is recently defined as a chronic, diffuse abnormality of the meibomian glands, commonly characterized by terminal duct obstruction and/or qualitative/quantitative changes 
in the glandular secretion. This may result in alteration of the tear film, symptoms of eye irritation, clinically apparent inflammation, and occurs in ocular surface disease. ${ }^{[25]}$ Chalazia were a significant finding in our study associated with the tarsal type of VKC. However, a recent study suggests that conjunctival inflammatory status, rather than upper tarsal conjunctival tissue remodelling, may affect the meibomian gland status in VKC patients. ${ }^{[26]}$ The eye lid disorders bring to attention the need for increased awareness of these presentation in association with $\mathrm{VKC}$ in this population.

The frequency of 'home' treatments in our study was low. This may be as a result of the use of patent medicine vendors in our environment. Up to $78 \%$ of children were untreated in our study, which is higher than reported by a similar population based study from Rwanda, but not as high as an earlier report from Djibouti in 1986. ${ }^{[18,27]}$ This lack of treatment may be as a result of the parents/caregivers not recognising the need to treat the condition, particularly as it does not result in acute visual loss. This may facilitate the chronicity of the disease and some of its signs, resulting in the destruction of the limbal palisades with conjunctivalisation of the peripheral cornea, stem cell deficiency, pseudogerontoxon, plaque and stromal melt, as our study recorded some of these complications. ${ }^{[28]}$

The proportion of children with punctate epitheliopathy was low, probably because most of the children in our study had mild disease and where in the quiescent phase. Furthermore, the study was conducted in the early phase of the dry season.

Subepthelial corneal scarring is reported in $9.9 \%$ of children. The cycle of corneal inflammation occurs as a result of a set of reciprocal interactions between the conjunctiva and the cornea, which results in damage to the corneal epithelium and corneal stoma. With repeated episodes of corneal involvement, the formation of shield ulcers, plaques, infectious keratitis, keratoconus, scarring, and limbal stem cell deficiency may occur. ${ }^{[17]}$ It is believed that about $60 \%$ of patients have repeated recurrences all year. ${ }^{[4]}$

Pseudogerontoxon was seen in $3.1 \%$ of children in our study. This lesion looks like a small segment of arcus senilis or gerontoxon, and is often the only clinical evidence of previous allergic eye disease. ${ }^{[29]}$

Corneal complications appear to be one of the earliest causes of visual impairment and can cause permanent decrease or loss of vision in children. ${ }^{[30]}$ Vision screening alone, although recommended in primary school children, will not identify VKC cases. Therefore, incorporating eye examinations into the routine vision screening is recommended. Early and proper recognition of the corneal complications of VKC at the community and primary health care level of Published by Sciedu Press health delivery is crucial as early, appropriate and adequate medical and surgical treatment can reduce the incidence of corneal scarring and visual impairment.

Children with VKC have been reported to have a high incidence of keratoconus and have more abnormal corneal topographic patterns compared with normal eyes. ${ }^{[31]}$ Keratoconus as well as complications of cataract and glaucoma were not seen in our study, probably because such complications are seen in late childhood and early adult years, more commonly after the chronic use of steroid medications for VKC. ${ }^{[32]}$

Investigations have shown the association between severe ocular allergy and dry eye. Clinical management of VKC is however usually focused just on classical symptoms and signs of the disease and on the risk of severe corneal involvement. ${ }^{[33]}$ This study used the SBUT to suggest tear film stability. It signals the timing of tear film beak-up (TFBUT) without the use of a diagnostic dye. The mean Symptomatic Tear Film Break Up Time of $<5$ seconds was seen in more children $(70 \%)$ with VKC, although there was no statistical significance or association with any clinical type. Clinically, this suggested high frequency of dry eyes in VKC cases may not be surprising as several studies have shown a reduced Break Up Time and abnormal Schirmer values in VKC. ${ }^{[34-37]}$ Furthermore, dry eyes appear to co-exist and even persist in the quiescent phases of the VKC. ${ }^{[33]}$ This may suggest a potential mechanism of damage of the ocular surface. The effect of environmental factors and other associated health related conditions such as a respiratory tract infection may bias the outcome of SBUT. The need for further observations to confirm tear film stability is important and a clinical trial of the addition of tear substitutes to the management of VKC to ascertain its efficacy may be useful. Similar to other reports, the difficulty of assessing the ocular surface signs in a pediatric population is sometimes challenging.

In conclusion, $\mathrm{VKC}$ is a debilitating ocular allergic disease which rarely results in permanent loss of vision initially. Long term follow-up of this cohort would be required to ascertain the overall risk of sight threatening complications including identifying risk factors that cause progression from the quiescent to active disease.

Most studies conducted in the country have been hospital based. This population study of primary school children in Nigeria contributes to the body of knowledge on VKC, further emphasizing the need for better case identification and appropriate treatment in the African community.

\section{Conflicts of InTERest Disclosure}

The authors declare that there is no conflict of interest regarding the publication of this paper. 


\section{REFERENCES}

[1] Leonardi A, Bogacka E, Fauquert JL, et al. Ocular allergy: recognizing and diagnosing hypersensitivity disorders of the ocular surface. Allergy. 2012; 67: 1327-37. PMid:22947083 https://doi.org/ 10.1111/all.12009

[2] Erich Knop, Nadja Knop. Anatomy and Immunology of the Ocular Surface. Niederkorn JY, Kaplan HJ (eds): Immune Response and the Eye. Chem Immunol Allergy. Basel, Karger. 2007; 92: 36-49.

[3] Girolamo N. Stem cells of the human cornea. British Medical Bulletin. 2011; 100(1): 191-207. PMid:21680602 https://doi .org/ $10.1093 / \mathrm{bmb} / \mathrm{ldr} 026$

[4] Lambiase A, Minchiotti S, Leonardi A, et al. Prospective, multicenter demographic and epidemiological study on vernal keratoconjunctivitis: a glimpse of ocular surface in Italian population. Ophthalmic Epidemiol. 2009; 16: 38-41. PMid:19191180 https://doi.org/10.1080/09286580802573177

[5] Vichyanond P, Pacharn P, Pleyer U, et al. Vernal keratoconjunctivitis: a severe allergic eye disease with remodeling changes. Pediatr Allergy Immunol. 2014; 25: 314-322. PMid:24438133 https : //doi.org/10.1111/pai.12197

[6] Eni EJ. Seasonal variation in hydrochemical parameters of ground water in calabar south, Cross River State, Nigeria. British Journal of Arts and Social Sciences. 2011; 3: 2046-9578.

[7] Bremond-Gignac D, Donadieu J, Leonardi A, et al. Prevalence of vernal keratoconjunctivitis: a rare disease? Br J Ophthalmol. 2008; 92(8): 1097-102. PMid:18356259 https://doi.org/10.1136/ bjo. 2007.117812

[8] Duke R, Odey F, De Smedt R. Vernal Keratoconjunctivitis in Public Primary School Children in Nigeria: Prevalence and Nomenclature. Epidemiology Research International. 2016.

[9] Stone KD. Atopic diseases of childhood. Curr Opin Pediatr. 2002; 14(5): 634-46. https://doi.org/10.1097/00008480-20021 0000-00012

[10] Small P, Frenkiel S, Becker A, et al. The Canadian Rhinitis Working Group. Rhinitis: A practical and comprehensive approach to assessment and therapy. J Otolaryngol. 2007; 36(Suppl 1): S5-S27.

[11] Lee T, Anderson S. Heterogeneity of mechanisms in exercise induced asthma. Thorax. 1985; 40: 481-487. https ://doi.org/10.1136/ thx.40.7.481

[12] Hanifin J, Rajka G. Diagnostic features of atopic dermatitis. Acta Derm Venereol. 1980: 92; 44-47.

[13] WHO. International Classification of Disease. 10th revision. H54 codes.

[14] Small RG, Sabates NR, Burrows D. The measurement and definition of ptosis. Ophthal Plast Reconstr Surg. 1989; 5(3): 171-5. https://doi.org/10.1097/00002341-198909000-00003

[15] Nally L, Ousler G, Abelson M. Ocular discomfort and tear film breakup time in dry eye patients: A correlation. Invest Ophthalmol Vis Sci. 2000; 4: 1436-1441.

[16] Abelson M, Ousler G, Nally L. Alternate reference values for tear film break-up time in normal and dry eye populations. Adv Exp Med Biol. 2002; 506(Part B): 1121-1125.

[17] Bonini S, Coassin M, Aronni S, et al. Vernal keratoconjunctivitis. Eye. 2004; 18: 345-351. PMid:15069427 https://doi.org/10.1 $038 / \mathrm{sj}$.eye 6700675

[18] De Smedt SK, Nkurikiye J, Fonteyne YS, et al. Vernal keratoconjunctivitis in school children in Rwanda: clinical presentation, impact on school attendance, and access to medical care. Ophthalmology. 2012 Sep; 119(9): 1766-72.

[19] De Smedt S, Wildner G, Kestelyn P. Vernal keratoconjunctivitis: an update. Br J Ophthalmol. 2013; 97: 9-14. PMid:23038763 https://doi.org/10.1136/bjophthalmol-2011-301376
[20] Soukiasian S, Rice B, Foster C. The T cell receptor in normal and inflamed human conjunctiva. Invest Ophthalmol Vis Sci. 1992; 33: 453-59. PMid:1531476

[21] Rao SK, Meenakshi S, Srinivasan B, et al. Perilimbal Bulbar Conjunctival Pigmentation in Vernal Conjunctivitis Prospective Evaluation of a New Clinical Sign in an Indian Population. Cornea. 2004; 23 : 3569. PMid:15097129 https://doi .org/10.1097/00003226-200 405000-00008

[22] Ajaiyeoba AI. Prevalence of atopic diseases in Nigerian children with vernal keratoconjunctivitis. West Afr. J. Med. 2003; 22(1): 15-17. PMid:12769299

[23] Duke RE, Lewallen S, Courtright P. Estimated Prevalence of Monocular Blindness and Monocular Severe Visual Impairment in Children of Cross Rivers State, Nigeria. Niger J Ophthalmol. 2014; 22: 66-8. https://doi.org/10.4103/0189-9171.154610

[24] Griffin RY, Sarici A, Unal M. Acquired ptosis secondary to vernal conjunctivitis in young adults. Ophthal Plast Reconstr Surg. 2006; 22 438-40. PMid:17117097 https ://doi .org/10.1097/01.iop.0 000246609.39499 . da

[25] Nichols KK, Foulks GN, Bron AJ, et al. The international workshop on meibomian gland dysfunction: executive summary.Invest Ophthalmol Vis Sci. 2011; 52(4): 1922-1929. PMid:21450913 https://doi.org/10.1167/iovs.10-6997a

[26] Qihua L, Hong J, Xiang J, et al. In vivo confocal microscopy of meibomian glands and palpebral conjunctiva in vernal keratoconjunctivits. Indian J Ophthalmol. 2015 Apr; 63(4): 327-330.

[27] Resnikoff S, Cornand G, Filliard G, et al. Limbal vernal conjunctivitis in the tropics. Rev Int Trachome. 1988; 3(4): 53-71.

[28] Buckley RJ. Vernal keratopathy and its management. Trans Ophthalmic Soc UK. 1981; 101: 234-8.

[29] Jeng BH, Whitcher JP, Margolis TP. Pseudogerontoxon. Clin Experiment Ophthalmol. 2004 Aug; 32(4): 433-4. PMid:15281982

[30] Solomon A. Corneal complications of vernal keratoconjunctivitis. Curr Opin Allergy Clin Immunol. 2015; 15(5): 489-94. PMid:26258926 https ://doi.org/10.1097/ACI . 0000000000 000202

[31] Totan Y, Hepsen IF, Cekic O, et al. Incidence of keratoconus in subjects with vernal keratoconjunctivitis: a videokeratographic study. Ophthalmology. 2001; 108: 824-827. https://doi.org/10.101 6/S0161-6420(00)00664-3

[32] Al-Akily AS, Bamashmus AM. Ocular complications of severe vernal keratoconjunctivitis (VKC) in Yemen. Saudi Journal of Ophthalmology. 2011; 25: 291-294. PMid:23960939 https://doi .org/10.1 016/j.sjopt. 2011.02.001

[33] Villani E, Strologo MD, Pichi F, et al. Dry Eye in Vernal Keratoconjunctivitis. Medicine (Baltimore). 2015 Oct; 94(42): e1648.

[34] Bonini S, Lambiase A, et al. Vernal keratoconjunctivitis revisited: a case series of 195 patients with long-term followup. Ophthalmology. 2000; 107: 1157-1163. https://doi.org/10.1016/S0161-642 0(00) 00092-0

[35] Bonini S, Schiavone M, et al. Conjunctival hyperresponsiveness to ocular histamine challenge in patients with vernal conjunctivitis. $\mathrm{J}$ Allergy Clin Immunol. 1992; 89: 103-107. https ://doi.org/10 .1016/S0091-6749(05)80046-6

[36] Bonini S, Bucci MG, et al. Allergen dose response and late symptoms in a human model of ocular allergy. J Allergy Clin Immunol. 1990; 86: 869-876. https://doi .org/10.1016/S0091-6749(05)801 48-4

[37] Hiroshi F, Ikuko T, Jun S, et al. Allergic conjunctivitis and dry eye. BJO. 1996; 80: 994-997. https://doi.org/10.1136/bjo.80.1 1.994 